\title{
Effects and optimal proposal analyses of soil and water conservation measures for disturbed accumulations of typical production and construction projects in Shenzhen City
}

\author{
Zhihua Zhang ${ }^{1,2, *}$, Qian Wang ${ }^{1,2}$, Hao Xie ${ }^{1,2}$, Jing Yang ${ }^{1,2}$, and Wensheng $\mathrm{Xu}^{1,2}$ \\ ${ }^{1}$ Changjiang River Scientific Research Institute of Changjiang Water Resources Commission, Wuhan 430010, China \\ ${ }^{2}$ Research Center on Mountain Torrent \& Geologic Disaster Prevention, Ministry of Water Resources, Wuhan 430010, China
}

\begin{abstract}
Due to the specific natural conditions and high intensity of human activities in Shenzhen, the characteristics of water and soil erosion of Shenzhen are prone and frequent. There are no large rivers, lakes and reservoirs in Shenzhen, and the rainwater storage capacity is unsubstantial that result in some problems such as ecological environment deterioration, river siltation, drainage pipe network blockage, and aggravation of flood disasters. The work of soil and water conservation in Shenzhen is still grim. In this paper, the sediment under different soil and water conservation measures were measured based on long-term observation of typical road engineering, river engineering and pipeline engineering in Shenzhen. Then, the effect of soil and water conservation measures implemented in these typical engineering were analyzed. At last, the optimal proposals of soil and water conservation measures for these typical engineering were proposed. This research aims to provide data support for the formulation and modification of soil and water conservation technical specifications for production and construction projects in Shenzhen.
\end{abstract}

\section{Introduction}

As a typical representative of rapid urbanization, Shenzhen has started urban soil and water conservation work since the 1990s. It has experienced three stages successively: large-scale development of soil erosion control in flat soil areas, comprehensive management of soil and water conservation in exposed mountain gaps and comprehensive management of water and soil conservation in drinking water source reservoirs. The area of soil erosion decreased from $184.99 \mathrm{~km}^{2}$ in 1995 to $39.17 \mathrm{~km}^{2}$ in 2019 [1], that the area of soil and water loss caused by human activities is $33.86 \mathrm{~km}^{2}$, accounting for $86.44 \%$ of the total area of soil and water loss, which is a typical representative of urban soil and water loss because of its obvious man-made attribute.

The research on the effect of soil and water conservation measures has made many achievements. Zhang et al. [2] made a general survey and detailed analysis of the characteristics of soil erosion and the adaptability of soil and water conservation measures combined with the historical data, field tests and investigations, and then the impact of human activities on soil erosion and the harm of it to local residents was analyzed based on the characteristics of soil and water loss in China. City as the typical area of the highly clustered activity of human and strong disturbance of the earth's surface, the soil erosion was more and more serious during the process of accelerating the construction of infrastructure, such as the continuous improvement of the bearing load, the great change of the land use situation, the sharply increase of city underlying surface impervious area, and the change of the hydrological cycle process [3]. Domestic scholars had deepened their studies on the benefits of soil and water conservation of Shenzhen's production and construction projects $[4,5]$ and supervision and management $[6,7]$ in combination with the problems of soil erosion in Shenzhen. However, there are few studies on the effect of soil and water conservation measures in urban production and construction projects. According to the sediment of disturbed accumulations in the typical production and construction projects under different soil and water conservation measures, there are also relatively few studies on the optimal proposal of soil and water conservation measures.

In this paper, the long-term observations of typical production and construction projects, such as road engineering, river engineering, and pipeline engineering in Shenzhen are conducted. The sediments under different rainfalls and soil and water conservation measures in different typical engineering are measured and dried indoor. Then, the effect of different soil and water conservation measures is analyzed to propose the optimal proposal for typical engineering. It aims to provide data support for the formulation and modification of soil and water conservation technical specifications for production and construction projects in Shenzhen.

\footnotetext{
${ }^{*}$ Corresponding author: zhangzh $@$,mail.crsri.cn
} 


\section{Monitoring objects and site sampling}

A number of typical production and construction projects, such as road engineering, river engineering, and pipeline engineering under construction in Shenzhen are determined. The road engineering include No. 35 municipal road, 2 and 4 sections of the eastern transit road, and 4, 5 and 6 sections of the outer ring highway of Shenzhen; the river engineering include Tangkeng Water comprehensive regulation project in Pingshan River basin and Loucun Water comprehensive regulation project in Maozhou River basin; the pipeline engineering is mainly natural gas high pressure pipeline project of Huadian Pingshan distributed energy project.

The soil and water conservation measures of urban production and construction projects mainly include temporary measures and vegetation measures. The temporary measures include cover, drainage ditch, blocking, sand settling pond. Among them, the soil and water conservation measures of river engineering mainly include temporary cover, stone cage nets and vegetation measures. A total of 210 samples are collected in this study. The sediments under different soil and water conservation measures are then analyzed through on-site sampling, indoor precipitation, drying, and weighting.

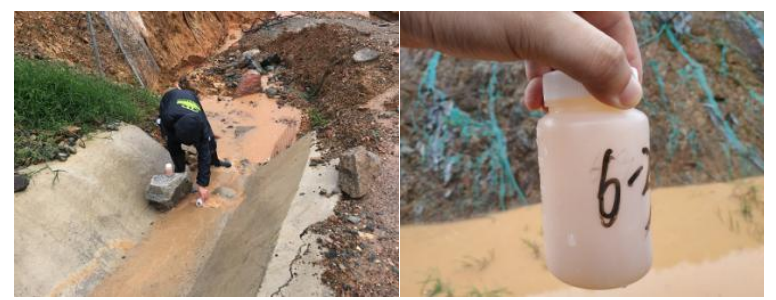

Fig. 1. On-site sampling and samples.

\section{Effect analysis of soil and water conservation measures}

\subsection{Road engineering}

After nearly a year of field observation, the runoff samples of No. 35 municipal road, 2 and 4 sections of the eastern transit road, and 4, 5 and 6 sections of the outer ring highway of Shenzhen during rainfall are collected for laboratory analysis. The samples then set aside for at least $24 \mathrm{~h}$. Followed by decanting clear supernatant, runoff samples are dried at $105{ }^{\circ} \mathrm{C}$ for estimating sediment yield. The soil and water loss of slope under different rainfall intensities and different temporary soil and water conservation measures are obtained.

Through several months of field sampling, the sediment yields of the slopes during the rainfall period under cover measure with different coverage ratios are observed, as shown in Fig. 2. When the coverage is less than $70 \%$, the sediment yield is linearly distributed with the coverage ratio, and the coverage ratio at the intersection of the trend line and the horizontal axis approximates $65 \%$. Therefore, it can be inferred that when the coverage ratio of slopes reaches over $65 \%$, the soil and water loss of the slope during the rainfall period is small, and the temporary measure of cover for soil and water conservation is effective.

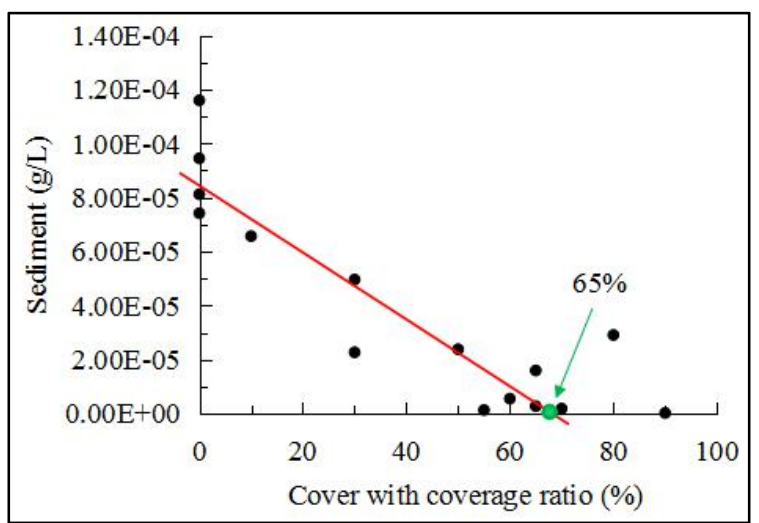

Fig. 2. Sediment yield under cover with different coverage ratios.

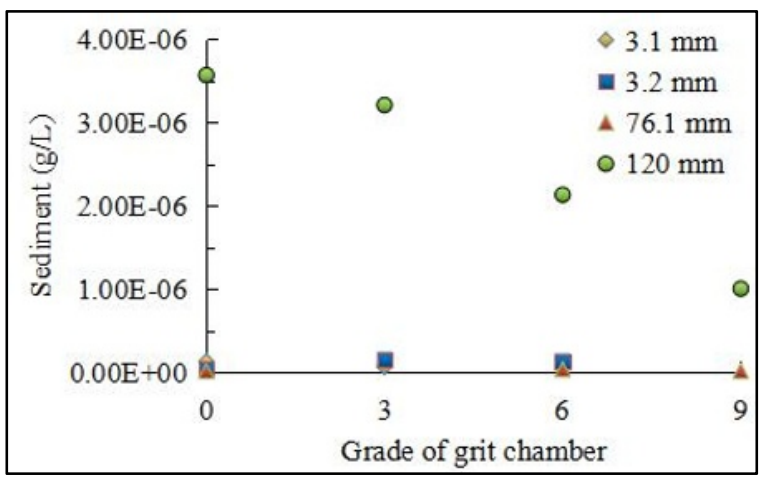

Fig. 3. Sediment yield under different grades of grit chamber with different rainfall.

As shown in Fig. 3, the sediment yield in the runoff decreases gradually with the increase of the grade of grit chamber under different rainfall intensities. Moreover, with the increase of rainfall intensity, the sediment yield in the grit chamber increases gradually. When the catchment flow passes through the grit chamber with three grades, the sediment in the flow is deposited, and the sediment yield at the outlet is reduced by $10.08 \%$ compared with that at the inlet. When the water flow passes through the 6 and 9 grades' grit chambers, the sediment yield at the outlet decreases by $40.34 \%$ and $71.99 \%$, respectively, compared with that without grit chamber.

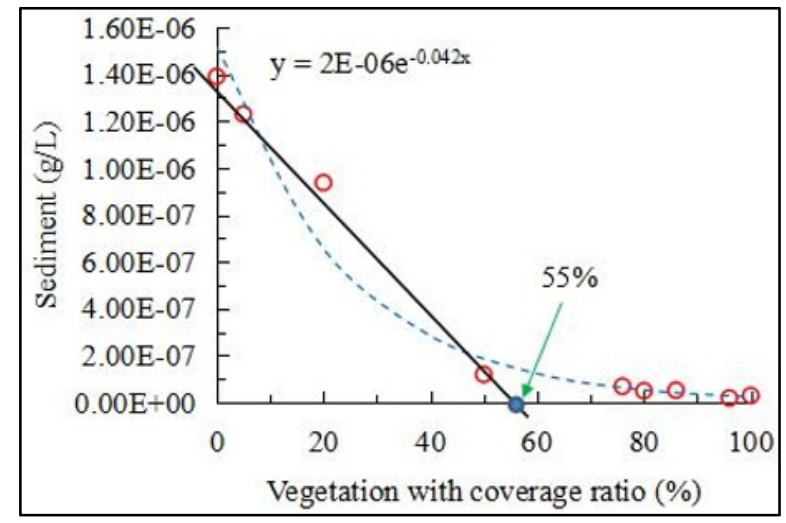

Fig. 4. Sediment yield of runoff at the slope foot under different coverage ratios of vegetation. 
Under different rainfall conditions, with the increase of vegetation coverage, the sediment yield in the runoff at the foot of slope gradually decreases. The relationship between sediment yield and the vegetation coverage is approximately exponential (the broken line shown in Figure 4). When the vegetation coverage ratio is less than $60 \%$, the sediment yield in the catchment water has a linear relationship with the vegetation coverage ratio, and the intersection point of trend line and abscissa is that the vegetation coverage ratio is $55 \%$. Compared with the effect of soil and water conservation under the temporary soil and water conservation measures, the vegetation coverage value is relatively small $(65 \%$ coverage), therefore, the plants have a stronger ability to reduce soil and water loss, which has an important relationship with the role of plant leaves and roots in soil and water conservation. Therefore, it can be inferred that when the vegetation coverage ratio reaches more than $55 \%$, the soil and water loss of the slope during the rainfall period is small, and plant measures on soil and water conservation is effective. Therefore, in the process of engineering construction, soil erosion of disturbed accumulation is greatly affected by vegetation, especially with the growth of vegetation, vegetation coverage is gradually increasing, soil and water conservation effect is also gradually enhanced.

\subsection{River engineering}

In the past year, the project team conducted field observation on the Loucun Water comprehensive regulation project in the Maozhou River basin and the Tangkeng Water comprehensive regulation project in the Pingshan River basin, respectively. Under different rainfall conditions, the water samples at the slope foot of the two sides of the river were sampled to analyze the sediment yield.

As shown in Table 1, when the slope is bare (such as $21.9 \mathrm{~mm}$ of rainfall and $48^{\circ}$ of slope), the catchment sediment yield at the top of the slope is less than that at the foot of the slope, indicating that soil and water loss occurs in the bare slope under the heavy rainfall. By comparing and analyzing the sediment yield at the foot of slope with different slope angles, it can be seen that with the increase of slope angle, soil and water loss on slope surface increases, and the effect of soil and water conservation by vegetation measures becomes worse. When the rainfall is $181.1 \mathrm{~mm}$, the sediment yield at the foot of the slope above the river (slope $48^{\circ}$ ) is higher than that at the top of the slope due to the damage of the cover measure and low vegetation coverage, indicating that even if the temporary soil and water conservation measures for the slope have been implemented, when the temporary measures have not been fully implemented and failed to play their role, soil and water loss still occurs.

Table 1. Sediment yield at the slope foot of the two sides of the river

\begin{tabular}{|c|c|c|c|c|}
\hline $\begin{array}{c}\text { Rainfall } \\
(\mathbf{m m})\end{array}$ & $\begin{array}{c}\text { Slope angle } \\
(\mathbf{\circ})\end{array}$ & $\begin{array}{c}\text { Vegetation coverage } \\
(\mathbf{\%})\end{array}$ & \multicolumn{2}{|c|}{ Sediment yield (g/L) } \\
\cline { 3 - 5 } & 44 & 50 & Top of slope & Foot of slope \\
\hline 9.3 & 48 & 10 & $3.00 \mathrm{E}-08$ & $0.00 \mathrm{E}+00$ \\
\hline 9.3 & 44 & 50 & $1.00 \mathrm{E}-08$ & $5.00 \mathrm{E}-08$ \\
\hline 21.9 & 48 & 0 & $5.00 \mathrm{E}-08$ & $1.00 \mathrm{E}-08$ \\
\hline 21.9 & 46 & 99 & $3.00 \mathrm{E}-08$ & $7.00 \mathrm{E}-08$ \\
\hline 82.8 & 48 & 99 & $5.00 \mathrm{E}-08$ & $0.00 \mathrm{E}+00$ \\
\hline 82.8 & 46 & 40 & $7.00 \mathrm{E}-08$ & $1.00 \mathrm{E}-08$ \\
\hline 181.1 & 48 & 40 & $3.00 \mathrm{E}-08$ & $7.00 \mathrm{E}-08$ \\
\hline 181.1 & & &
\end{tabular}

\subsection{Pipeline engineering}

Table 2. Monitoring data of natural gas high pressure pipeline engineering of Shenzhen Huadianpingshan distributed energy project.

\begin{tabular}{|c|c|c|c|c|c|}
\hline $\begin{array}{c}\text { Rainfall } \\
(\mathbf{m m})\end{array}$ & $\begin{array}{c}\text { Cover } \\
\mathbf{( \% )}\end{array}$ & $\begin{array}{c}\text { Vegetation } \\
\mathbf{( \% )}\end{array}$ & $\begin{array}{c}\text { Sediment yield } \\
\text { before the blocking } \\
\mathbf{( g / L )}\end{array}$ & $\begin{array}{c}\text { Blocking } \\
\text { interval } \\
(\mathbf{m})\end{array}$ & $\begin{array}{c}\text { Sediment yield } \\
\text { after the } \\
\text { blocking (g/L) }\end{array}$ \\
\hline 9.5 & 20 & 85 & $9.00 \mathrm{E}-08$ & 40 & $6.00 \mathrm{E}-08$ \\
\hline 9.5 & 20 & 85 & $9.00 \mathrm{E}-08$ & 10 & $1.00 \mathrm{E}-08$ \\
\hline 10.5 & 70 & 85 & $1.50 \mathrm{E}-07$ & 40 & $9.00 \mathrm{E}-08$ \\
\hline 10.5 & 70 & 85 & $1.50 \mathrm{E}-07$ & 10 & $3.00 \mathrm{E}-08$ \\
\hline 41.8 & 70 & 85 & $5.90 \mathrm{E}-07$ & 40 & $3.70 \mathrm{E}-07$ \\
\hline 41.8 & 70 & 85 & $5.90 \mathrm{E}-07$ & 10 & $3.00 \mathrm{E}-08$ \\
\hline
\end{tabular}

The natural gas high-pressure pipeline project of Shenzhen Hudianpingshan distributed energy project is located in the hilly area. The project spans a hill, and the slope is implemented with the mortar stone blocking and the newly added mortar stone drainage ditch measures. The vegetation coverage ratio is approximately $85 \%$ with carpet grass and dogtooth root grass. The project team analyzed the sediment yield in the drainage ditch at different intervals of blocking, as shown in Table 2 .

With the increase of implement time, the coverage ratio of cover on the disturbed accumulation was damaged and gradually decreased. As shown in Table 2, by comparing the sediment yields before and after the blocking, the mortar stone blocking can effectively reduce the sediment, and the water and soil conservation effect is great. When the blocking interval is $10 \mathrm{~m}$, the 
reduction rate of sediment is $80 \%-94.92 \%$. When the interlocking space is $40 \mathrm{~m}$, the sediment content is reduced by $33.3 \%-40 \%$.

\section{Optimal proposal of soil and water conservation measures}

\subsection{Road engineering}

Under the condition of single temporary soil and water conservation measure, when the slope coverage rate reaches more than $65 \%$, the soil and water loss of the slope during the rainfall period is small, and the effectiveness of cover measure is great. For grit chamber, the project should strictly set different grades of grit chamber accordance with the project budget and construction schedule. Theoretically, the higher the grades of grit chamber is, the more obvious the effect of sediment settling and reducing the flow velocity will be.

In the process of engineering construction, soil erosion of slope is greatly affected by vegetation, especially with the growth of vegetation, slope vegetation coverage is gradually increasing, and the soil and water conservation effect is also gradually enhanced. The vegetation coverage ratio is more than $55 \%$, and the vegetation measure on soil and water conservation is effective. Under the condition of single temporary soil and water conservation, the effect of vegetation is better than that of cover measure. As both of them have certain shortcomings, the combination of the measures of cover and vegetation results in better effect of soil and water conservation and environmental greening.

\subsection{River engineering}

In the course of river regulation engineering construction, the slope on both sides of the river is carried out in combination with vegetation and cover measures, and the soil and water conservation effect and environmental greening effect are excellent. At the same time, engineering measures such as stone cage net or mortar masonry stone at the foot of the slope can effectively prevent slope collapse. In the process of construction, the coverage ratio of slope covering on both sides of the river reaches more than $65 \%$, which can effectively prevent the soil and water loss. In the natural recovery period of the project, the vegetation coverage on both sides of the river reaches more than $55 \%$, and the effect of vegetation measure on soil and water conservation is obvious.

\subsection{Pipeline engineering}

Most of the soil and water conservation measures in pipeline engineering can exert good soil and water conservation effect, but some of them can not be rationally matched with the growth of vegetation, resulting in poor plant growth. In addition, due to the special geographical conditions in the project area, some soil and water conservation measures are implemented, but, unreasonable.
At present, for the pipeline engineering construction process, the combination and implementation of the cover and vegetation measures is conducive to soil and water conservation and environmental greening. After the completion of the project, the measures of blocking and drainage ditch of the grouting stone could be combined with the vegetation measures of carpet grass or dogroot grass to cover the hillside, and the effect of soil and water conservation will be practical and perfect.

\section{Conclusions}

In the analysis of the prevention effect of soil and water loss by the temporary measures in road engineering projects, it is found that the sediment yield of the catchment at the foot of the slope during the rainfall period is still in a non-linear relationship with the slope coverage rate. When the coverage ratio of cover measure is $10 \%$ and $50 \%$, respectively, the sediment yield is reduced by $11.46 \%$ and $67.92 \%$ compared with the bare slope, respectively. When the coverage ratio of cover reaches more than $65 \%$, the soil and water loss of the slope during the rainfall period is small, and the temporary measures for soil and water conservation of cover are effective.

When the vegetation coverage ratio is more than $76 \%$, the sediment content decreases by $92.62 \%$ compared with that of $20 \%$. In the process of engineering construction, the soil erosion of disturbed accumulation is greatly affected by vegetation, especially with the growth of vegetation, the vegetation coverage of slope is gradually increasing, soil and water conservation effect is also gradually enhanced. When the vegetation coverage ratio reaches more than $55 \%$, the soil and water loss of the slope during the rainfall period is small, and the effect of vegetation measure on soil and water conservation is obvious.

Therefore, during the engineering construction, the soil and water conservation temporary measure of cover could not be implemented by $100 \%$, but should ensure that the coverage ratio of it is more than $65 \%$. And the vegetation seed should be protected in the early stage of natural recovery until the vegetation coverage ratio is more than $55 \%$.

\section{Acknowledgements}

This work was financial supported by the National Key Research and Development Project of China (No. 2017YFC1502503) and the Science and Technology Special Plan Fund of Water Resources Bureau of Shenzhen Municipality (No. CKSK2017820/TB).

\section{References}

[1] Water Resources Bureau of Shenzhen Municipality. Shenzhen bulletin of soil and water conservation (2019) (In Chinese)

[2] X.C. Zhang, M.G. Shao, S.Q. Li, K.S. Peng, J. Geogr. 1 Sci 14(3), 259-274 (2004)

[3] Y.X. Wang, Landscape Architect 5, 43-48 (2013) (In Chinese) 
[4] J. Ye, Pearl River Water Transportation 46(6), 214 216 (2018) (In Chinese)

[5] Y.P. Chen, Heilongiiang Hydraulic Sci. Technol 46(6), 214-216 (2018) (In Chinese)

[6] L. Ren, W.S. Xu, J.W. Sun, J.Q. Huang, P.C. Zhang, Soil Water Conserv. in China 2, 14-15+24 (2019) (In Chinese)

[7] Y.P. Shao, F. Wu, H.H. Zhang, X. Yang, Soil Water Conserv. in China, 4, 12-14 (2019) (In Chinese) 